\title{
Intercultural Managerial Ability and Leadership: Challenges, Controversies, and Prospects
}

\author{
Vasilios Andrikopoulos \\ University of Patras, Greece
}

Received: Nov. 24, 2021

Accepted: Feb. 1, $2022 \quad$ Published: February 1, 2022

doi:10.5296/jse.v12i1.19373 URL: https://doi.org/10.5296/jse.v12i1.19373

\begin{abstract}
This study attempted to present, conceptualize and recontextualize intercultural managerial ability and leadership through the examination of the relevant discourse on the topic. Data analysis revealed that the two concepts are inextricably linked to each other constituting a holistic approach to school managers and leaders' performing their tasks successfully in intercultural settings. Moreover, the numerous challenges posed, and the prospects arisen were discussed and analyzed, so as to shed light to the dimensionality and differentiation that characterize the multiple models of intercultural competence along with managerial and leadership skills having to be nurtured, maintained as well as upgraded through initial and continuous professional development upon preparation of new, potential and proactive school leaders. In a nutshell, the present study enriches our understanding about managerial ability and leadership that is to be exercised in an intercultural school context, giving impetus to other studies in this field.
\end{abstract}

Keywords: intercultural managerial ability, leadership, challenges, controversies, prospects 


\section{NInstitutemk}

\section{Introduction}

The multicultural reality of modern societies is intertwined with the need for effective management of the cultural pluralism that emerges due to multicultural coexistence and equal recognition of diversity, based on the acceptance of difference and respect for human rights. In the context of education, these processes encounter inherent obstacles related to the nature, structure and culture of educational systems and schools, which do not have the characteristics of interculturalism and inclusiveness (Hajisoteriou \& Angelides, 2018).

Therefore, changes are needed that foster the development of intercultural communication and interaction skills at the school level, starting with school leaders. In particullar, the intercultural ability and competence of school leaders but also the exercise of effective leadership on their part can contribute to the change and improvement of schools through the cultivation of an intercultural, inclusive culture. Thus, a key parameter that influences the promotion and implementation of the goals of intercultural education is the intercultural managerial ability of school and educational leaders (Hajisoteriou, Karousiou, \& Angelides, 2018).

In this context, the present study attempts to outline the discussion unfolded about intercultural managerial ability starting from the conceptual approach of intercultural competence and the models that theorize it, then analyzing the importance of the intercultural competence of the school leader and highlighting the close relationship between intercultural managerial ability and intercultural leadership. Finally, the discussion-and-conclusion section summarizes the findings and results of the theoretical research carried out and provides concluding remarks as well as implications for future studies.

\section{Models of Intercultural Competence}

\subsection{Intercultural Competence as a whole}

Intercultural competence, in the light of intercultural skills, seems to consist of five elements: 1 . knowledge of other social groups, their practices and processes of interaction at the interdisciplinary and wider social level, 2. behaviors (savoir etre), such as curiosity, the obvious state of readiness and lack of distrust in other cultures, 3. the pursuit of meaning, interpretation and explanation of the characteristics of other cultures in direct relation to the savage culture (savoir comprendre), 4. acquisition of skills that favor exploration and interaction, the acquisition of new knowledge about a culture, as well as the application of this knowledge in real life and the adoption of a positive attitude towards the different (savoir apprendre), and 5. the development of critical intercultural cognition and intercultural education, which facilitates and promotes the possibility of critical evaluation of the relevant and other cultures (savoir s' engager) and cross-cultural comparison (Byram, 2014).

Deardorff $(2006 ; 2015)$ argues that intercultural competence is directly related to skills that enable intercultural encounter, in which prevail conditions for adequate and effective communicative interaction in intercultural situations. Thus, it is pointed out that this is an ongoing process, which includes knowledge, skills, attitudes and behaviors and can be represented in the form of a pyramid, based on specific abilities and predispositions, such as respect for the different, positive self-perception, empathy. and the ability to transform the 


\section{Al Macrothink}

semantic context of experiences that encourage intercultural dialogue and the forging of intercultural ties and relationships.

A different approach to intercultural competence is one that classifies it in the category of types of intelligence. Intercultural intelligence is related to the ability of individuals to function and manage situations effectively in multicultural contexts. In this way, intercultural competence acquires broader dimensions, learning, didactic, psychodynamic, while the reference framework of the concept under study is expanded to include the practices followed by individuals and multicultural composition groups, as they try to develop action and participate in intercultural interactions (Ang \& Inkpen, 2008; Ang, Rockstuhl, \& Tan, 2015).

\subsection{Intercultural Understanding and Awareness}

The concept of intercultural understanding refers to the epistemological field of intercultural competence and, in particular, to the acquisition of knowledge by individuals about their own culture and civilization, as well as about other cultures, about the similarities and differences between cultures, with obvious behavioral manifestation of intercultural understanding in the field of intercultural interaction and communication. However, cultural knowledge, while a prerequisite, is not, however, equivalent to gaining intercultural understanding, as cultivating and developing a positive attitude towards other cultures is just as important. The attitude of individuals towards cultural diversity is directly related to the level of intercultural awareness, in which they find the emotional response of individuals to cultural difference (Bennett, 2011; 2014).

Intercultural awareness, in turn, is enhanced by intercultural contact and encounter and contributes to the acquisition of experiences and the way in which individuals perceive cultural difference, record it in their reports by building their own intercultural capital (Taylor, 2014). This approach refers to the original model of Bennett (1986), which emphasizes the phases or stages of intercultural awareness, starting from ethnocentrism (the idea that the dominant culture of a country is unique and irreplaceable) and ending in ethno-relativism (culture-bounded conventional and interdependent principles and practices) (Hammer, 2012).

\subsection{Intercultural Communication Competence}

Other approaches link intercultural competence with intercultural communication and the knowledge, skills and motivations that facilitate and enable it. Thus, intercultural competence is understood as composed of a series of factors that promote verbal and non-verbal communication through appropriate and effective manifestations and communication situations. In this context, intercultural communication skills include interpersonal communication and the context in which it takes place, the appropriateness of media and methods of communication and the knowledge, motivation and communication readiness of the individual. Moreover, intercultural communication skills help carry out effective communication with the mediation mutually agreed codes and language tools in large and important intercultural differences in conditions and particularly in cases where disparate created and often contradictory interpretations and expectations of the context of communication (Pedersen, 2010; Koester \& Lustig, 2015). 


\section{Al Macrothink}

An important role in the process of intercultural communication is played by the verbal and social environment, namely the contexts, which facilitate the realization of communication between people from different cultures. Thus, the possibility of conflicts that intercultural interaction can bring about is reduced, when individuals and groups do not have the required intercultural competence. Finally, intercultural communicative competence allows intercultural relationship and enhanced through intercultural experience, intercultural education, motivation, positive attitude to globalization, intercultural dialogue, and empathic listening (Koester \& Lustig, 2015; Perry \& Southwell, 2011).

\subsection{The intercultural competence of the school leader}

"Intercultural competence is defined as the knowledge, attitudes, predispositions, and policies in a system, organization, or individual that enhance effective interaction with other cultural groups" (Hadjisoteriou \& Angelides, 2016, p. 52). In relation to the school principal, intercultural competence refers to the ability of school administration and leadership to respond with respect, sensitivity and understanding to the effects of cultural, linguistic and religious diversity as well as differences arising from ethnic origin and political views. This implies the acceptance and embracement of the cultural diversity as a necessary condition for the successful implementation of the goals of the school organization, by encouraging individuals to commit to achieving these goals, ensuring and maintaining the harmonious cooperation of the members of the organization and an impartial, unbiased and at the same time fair attitude towards any kind of differentiation emerging (Polat \& Olcum, 2016, p. 72).

Based on the models of intercultural competence, Frawley, Fasoli, D'Arbon , \& Ober (2010) classified intercultural educational leadership skills in the following four categories: personal, relational, professional and organizational. At the core of personal and relational skills is a sense and self-awareness within an intercultural world, intercultural self-reflection especially in relation to the leading and managerial role exercised within school communities and the personal values that guide their work as well as the ability to build mutually beneficial intercultural relationships, governed by values of respect and trust.

Alongside, intercultural professional skills focus on exercising the administrative and managerial role of school leaders as well as on taking initiatives and action in complex and changing conditions, which are formed in the context of the cultural pluralism of modern societies. In this light, school leaders have the opportunity to decide with discretion and to act in order to improve school environments, especially from the point of view of promoting inclusion and social justice, when confronted with conflicting and hostile views about culture diversity and practices that undermine intercultural school education (Frawley et al., 2010).

Similarly, organizational skills enhance the ability of school leaders to create an educational environment conducive to cultural diversity and variation, to delegate authority and to distribute responsibilities among teachers. Thus, it is possible to implement changes related to the transformation of schools into intercultural and inclusive learning communities. Therefore, intercultural skills promote the successful handling and effective implementation of the administrative work and the role that intercultural school leadership is called to play (Frawley et al., 2010). 


\section{Ml Macrothink}

However, the intercultural readiness of school leaders seems to differ from intercultural competence. More specifically, Frawley, Dang, \& Kittiphanh (2015) argue that intercultural competence refers to knowledge, skills and positive attitudes acquired in the past and make the individual interculturally capable of responding to the demands and priorities set at the present time. Therefore, it is pointed out that intercultural readiness concerns the control of the differentiated and pluralistic educational environment, while intercultural competence is related to the evolving processes of learning and intercultural development.

Nevertheless, the habitus of the pioneer school leader does not seem to include increased intercultural skills. Thus, it can be transformed through continuing professional development programs that aim to acquire knowledge of the various manifestations of alterity and cultural diversity and contribute to the cultivation and enhancement of intercultural skills through experiences of intercultural interactions and meeting contacts with people from differential cultural backgrounds and environments (Hansuvadha \& Slater, 2012; Pöllmann, 2016).

Thus, for example, it would be beneficial for both school leaders and the school community as a whole, if principals participate in educational trips, with visits to other cultures inside and outside their country. Also, information and knowledge about other cultures and engaging in multicultural education issues, as well as intercultural professional development, seem to contribute to cultivating positive attitudes towards diversity, thus facilitating the professional development and inclusive ability of school leaders (Frawley \& Fasoli, 2012; Hansuvadha \& Slater, 2012).

Polat, Arslan, \& Olcum (2016), on the other hand, emphasize the importance of personal opinions and perceptions of school leaders in the study of intercultural competence, as well as previous experience and approach to diversity issues on their part are determinants of change semantic framework and their assumptions, which can be achieved through the acquisition of intercultural skills. Thus, the above researchers argue that transforming the perspective of school principals and the consequent diversification of their frame of reference through the acquisition and consequent utilization of intercultural understanding and awareness-raising skills can contribute to a more complete, equal, empathetic approach to cultural diversity and difference.

Essentially, the study of intercultural managerial ability incorporates deciisively the need for retraining of principals, which is intertwined with new duties and responsibilities and responds to the demand for fulfillment of their role as both school leaders and executives in the modern multicultural school reality. In this context, the harmonization of personal and professional identity of school leaders is sought, in order to achieve perfect cooperation of teachers within the school but also between the school, parents of students and the local community, in order to implement inclusive practices at the local level (Zembylas \& Iasonos, 2010).

In their research, Barakat, Reames, \& Kensler (2019) found that multicultural school principals perceive intercultural understanding, empathy, and distributive leadership with a strong sense of social responsibility and genuine interest in people as elements that make schoolchildren leaders able to cope with the difficulties of managing complex environments, as well as to develop intercultural competence skills. They also point out that intercultural leaders need to 


\section{Macrothink}

have intercultural communication skills so that they can interact effectively with immigrant students and teachers and be receptive to diversity without prejudice or bias.

The study by Keung \& Rockinson-Szarkiw (2013) found a statistically significant relationship between intercultural intelligence and transformational leadership. Thus, it was found that school principals with increased intercultural intelligence were able to exercise transformative, inclusive leadership and more effectively manage complex, multicultural learning environments. However, researchers point out that transformational school leaders with a positive attitude towards diversity are not always aware of the latent way in which school and educational practices favor and promote the school success of some students and the marginalization of others.

This means that intercultural skills must be combined with good administrative and organizational skills of school and educational leaders, being a challenge and at the same time an important goal, which can be put into practice with the help of guidance and mentoring. In this way, mentoring can contribute to enhancing intercultural skills of school leaders and inclusive leadership formation, which in turn facilitates the creation and consolidation of a more favorable to inclusive diversity culture. The educational and administrative know-how, the accumulated experience and often the enhanced knowledge and training of school leaders in matters of intercultural leadership can contribute to the promotion of the intercultural competence of younger school principals and the emergence of inclusive leadership (Aldhaheri, 2017).

Therefore, it has been shown that intercultural managerial ability is directly related to the exercise of intercultural leadership and vice versa intercultural leadership presupposes and implies intercultural managerial ability. The next section presents in more detail the discussion concerning the relationship between intercultural managerial ability and intercultural leadership.

\section{Intercultural managerial ability and intercultural leadership}

Vassallo (2016) argued that intercultural leadership pertains the leaders' ability to understand and make sense as well to manage and lead effective multicultural schools. Their actions and behavior are related to the level of intercultural competence they possess, as well as to the leadership style and practices they prefer in the context of their agency. In addition, intercultural competence increases as ethnocentric approach to resolving school issues decreases on a daily basis. In addition, the school environment itself, the relationships they develop with the teaching staff, the students and their parents influence and perhaps to some extent define the context in which a school leader is called to perform their duties and take on intercultural action.

However, it is not uncommon for school leaders to have increased intercultural competence, while teachers face difficulties in intercultural relationships, especially with immigrant-biography students. Similarly, in many cases, teachers appear to have enhanced intercultural knowledge and readiness, intercultural understanding and communication skills, while school leadership remaining faithful to its administrative work and its formal, 


\section{Al Macrothink}

institutional role is unable to support teachers in their endeavor, that is to promote the principles and practices of intercultural education (Lahdenperä, Gustavsson, Lundgren, \& von Schantz-Lundgren, 2016).

Thus, it is pointed out that school leaders need to have intercultural skills in order to be able to promote the educational and school success of all students without exception in a way that cultivates new intercultural identities and inclusive skills. More specifically, intercultural managerial ability enables school leaders to encourage and support teachers in their work and specifically in recognizing the cultural diversity of their classrooms as a comparative advantage, cognitive resource and learning opportunity (Ghosh, Huang, \& Sun, 2020; Hadjisoteriou \& Angelides, 2016).

Thus, in addition to managerial ability, there is also the ability to exercise intercultural educational leadership that accepts and takes for granted cultural diversity in an increasingly globalized and ever-changing world. The emergence of intercultural, inclusive leadership requires participation in professional development programs aimed at acquiring intercultural communication skills. The need for intercultural leadership arises as a logical necessity deriving from the continuing increase in the number of students with immigrant biographies attending schools, which poses a challenge to educators and school leaders as well (Hadjisoteriou \& Angelides, 2016).

The latter are called upon to successfully manage and resolve intercultural conflicts and disputes, which arise in interaction and are often hotbeds of disagreement. Therefore, continuous professional development for school leaders, aimed at enhancing their intercultural competence, is an important first step in implementing appropriate leadership models, responding to the call for inclusion and equal treatment of cultural diversity within and outside schools, in order for the intercultural capacity of education administrators to promote social justice (Cherkowski \& Ragoonaden, 2016).

After all, this seems to be the orientation of intercultural leadership, the fight against social injustice and inequality and ensuring the equal participation of all students in the educational process. Thus, school leaders with intercultural managerial ability are capable of moving away from traditional, dominant school structures based on ethnocentrism and the idea of cultural identity and develop critical intercultural awareness and cognition through reflective processes. Similarly, they can work to bring about change and transformation in schools, which will allow and encourage the cultivation of an interculturally sustainable school culture (Zembylas, 2010; Furman, 2012).

At the same time, intercultural, inclusive school leaders implement a wide range of school policies and practices, creating environments that orient and promote social activism. Such policies include an anti-prejudice education agenda, the recruitment of teachers belonging to minorities or immigrants, and the nurturing and development of an open and supportive school culture with inclusive characteristics in which exclusion practices are identified, recognized, challenged, and exposed, until they are eliminated (Hansuvadha \& Slater, 2012).

Consequently, successful leaders operating in environments of cultural pluralism (should) have 


\section{Macrothink}

Journal of Studies in Education

ISSN 2162-6952

2022, Vol. 12, No. 1

intercultural competence, as this becomes an obvious necessity especially if school principals are required to be able to treat different cultural groups equally through the learning that builds contact with different cultures and recognizing the complexities of cultural exchange. In addition, intercultural competence is intertwined with the development of post-modern conceptions of the nature and subsistence of cultures as unstable mixtures of uniformity and diversity (Hajisoteriou \& Angelides, 2014).

\section{Discussion and Conclusion}

This study attempted to provide a useful and deep insight as well, as it aspired to shed light on the challenges, the prospects and the controversies arising in regard to intercultural school leadership and managerial ability. Thus, our study was aimed at enriching our understanding about such a complex and multifaceted issue by examining, analyzing, and reflecting upon the officially presented discourse on this topic. Based on the literature review presented above, it can be stated that intercultural managerial ability has a complicated meaning and definition, since it articulates two sub-concepts, that is intercultural competence and the ability to exercise management and leadership with an intercultural orientation. The various nodels proposed for intercultural managerial ability and intercultural school leadership correspond to the models and approaches relate to intercultural ability and competence.

This means that intercultural knowledge and cognition, sensitivity and understanding as well as enhanced communication skills constitute the frame, wherein intercultural managerial skills can be nurtured, and intercultural leadership can flourish. Accordingly, leadership styles, such as the distributed and transformational ones, seem to provide a fertile ground for the establishment of intercultural leadership, as they inspire and motivate teachers and students to embrace cultural difference and alterity promoting democratic values and principles associated with intercultural education.

Moreover, managerial ability with intercultural orientation needs to be fostered through continuing professional development. School principals leading schools that thrive in intercultural settings ought to be properly prepared and effectively supported by participating in in-service training that focuses on intercultural leadership skills. To put it another way, experienced as well as new school leaders, in order to manifest proactive behavior and deliver best learning outcomes for all students, need authentic intercultural lifelong learning experiences and cross-cultural contact throughout their work life. As school leaders' habitus and predominant dispositions and beliefs regarding diversity and cultural differences seem to be transformed by professional development, intercultural professional development is considered to be a fundamental aspect of successful leadership having a profound impact on school improvement and school culture accepting the otherness.

Concomitantly, intercultural managerial ability is intertwined with specific skills that enable school leaders to work for establishing an inclusive school culture. In this way, intercultural leadership is inextricably linked to intercultural managerial ability or, more precisely, being another manifestation of it, as it encourages the cultivation of intercultural competence in teachers and students by strengthening the intercultural capital of the school. Accordingly, intercultural reciprocity and synergies promoting social justice and cohesion could lead to 
more inclusive schools and societies as well. Thus, intercultural management competently engages the role of school principals, school and educational leaders, with the ultimate goal of promoting interculturalism and inclusiveness of school and education systems. Given the key position of school leadership to implement changes that contribute to school improvement, it is vital the acquisition of intercultural skills, in order that school leaders are able to take action towards the realization of the imperatives of education for human rights and intercultural education.

After all, the intercultural, inclusive nature of the education and pedagogy itself sets specific priorities and goals to be achieved through the enactment of homologous policies and practices requesting school leaders to undertake initiatives against the marginalization and, in many cases, the exclusion of students that belong to other ethnicities and cultures other than the dominant one. This means that intercultural school leadership and management shows to have a deep impact on everyday school life and subsequently a more practical dimension that was presented and analyzed in this study as well. In this way, our study contributes to the relevant discussion regarding intercultural school management and leadership by conceptualizing, recontextualizing and clarifying managerial and leading ability that should and can be possessed by school principals and educational executives in order to fulfill their roles and duties in the intercultural school settings that have been arisen.

All in all, this study deepens our understanding about intercultural managerial ability and leadership and at the same time gives impetus for further research in this field. Taking into account the numerous challenges posed and the very interest that captures the intercultural school leadership, it seems reasonable to assert that intercultural leadership going hand-in-hand with managerial ability is of vital importance to be nurtured among prospective school leaders. Future studies could investigate the intercultural competence of school principals, the impact they could have on their schools and the intercultural action undertaken by school principals through the implementation of specific practices in accordance with the other tasks should be performed.

\section{References}

Aldhaheri, A. (2017). Cultural intelligence and leadership style in the education sector. International Journal of Educational Management, 31(6), 718-735. https://doi.org/10.1108/IJEM-05-2016-0093

Ang, S., \& Inkpen, A. C. (2008). Cultural intelligence and offshore outsourcing success: A framework of firm-level intercultural capability. Decision Sciences, 39(3), 337-358. https://doi.org/10.1111/j.1540-5915.2008.00195.x

Ang, S., Rockstuhl, T., \& Tan, M. L. (2015). Cultural intelligence and competencies. International Encyclopedia of Social \& Behavioral Sciences, 5, 433-439. https://doi.org/10.1016/B978-0-08-097086-8.25050-2

Barakat, M., Reames, E., \& Kensler, L. A. (2019). Leadership preparation programs: Preparing culturally competent educational leaders. Journal of Research on Leadership Education, 14(3), 212-235. https://doi.org/10.1177/1942775118759070 
Bennett, M. J. (1986). A developmental approach to training for intercultural sensitivity. International Journal of Intercultural Relations, 10(2), 179-196. https://doi.org/10.1016/0147-1767(86)90005-2

Bennett, M. (2011). Developing intercultural competence. Retrieved 23 October 2019, from http://www.pindex.com/uploads/post_docs/1Analytic-ICIInterculturalCompetence (PINDEX-DOC-14711).pdf

Bennett, J.M. (2014). Intercultural competence: vital perspectives for diversity and inclusion. In B.M. Ferdman \& B.R. Deane (Eds), Diversity at work: The practice of inclusion (pp. 155-176). Oxford: Wiley-Blackwell.

Byram, M. (2014). Twenty-five years on-from cultural studies to intercultural citizenship. Language, Culture and Curriculum, 27(3), 209-225. https://doi.org/10.1080/07908318.2014.974329

Cherkowski, S., \& Ragoonaden, K. (2016). Leadership for diversity: Intercultural communication competence as professional development. Teacher Learning \& Professional Development, 1(1), 33-43.

Deardorff, D. K. (2006). Identification and assessment of intercultural competence as a student outcome of internationalization. Journal of Studies in International Education, 10(3), 241-266. https://doi.org/10.1177/1028315306287002

Deardorff, D. K. (2015). A 21st Century Imperative: integrating intercultural competence in Tuning. Tuning Journal for Higher Education, 3(1), 137-147. https://doi.org/10.18543/tjhe-3(1)-2015pp137-147

Frawley, J., Fasoli, L., D’Arbon, T., \& Ober, R. (2010). The linking worlds research project: Identifying intercultural educational leadership capabilities. Leading and Managing, 16(1), $1-15$.

Frawley, J., \& Fasoli, L. (2012). Working together: Intercultural leadership capabilities for both-ways education. School Leadership \& Management, 32(4), 309-320. https://doi.org/10.1080/13632434.2012.708328

Frawley, J., Dang, K. A., \& Kittiphanh, D. (2015). Productive confusion: advancing intercultural perspectives through a multicultural professional development program for educational leaders. Journal of Praxis in Multicultural Education, 9(1), 1-10. https://doi.org/10.9741/2161-2978.1077

Furman, G. (2012). Social justice leadership as praxis: Developing capacities through preparation programs. Educational Administration Quarterly, 48(2), 191-229. https://doi.org/10.1177/0013161X11427394

Ghosh, D., Huang, X., \& Sun, L. (2020). Managerial Ability and Employee Productivity. In L.L. Burney (Ed.), Advances in management accounting (pp. 151-180). Bingley: Emerald Publishing Limited. 
Hajisoteriou, C., \& Angelides, P. (2014). Facing the 'challenge': School leadership in intercultural schools. Educational Management Administration \& Leadership, 42(45), 65-82. https://doi.org/10.1177/1741143213502194

Hajisoteriou, C., \& Angelides, P. (2016). School leadership for intercultural education. In C. Hajisoteriou \& P. Angelides (Eds.), The globalisation of intercultural education: The politics of macro-micro integration (pp. 175-196). London: Palgrave Macmillan.

Hajisoteriou, C., \& Angelides, P. (2018). Europeanization and intercultural education: From the supranational to the school level. Zephyr: Interaction. (In Greek)

Hajisoteriou, C., Karousiou, C., \& Angelides, P. (2018). Successful components of school improvement in culturally diverse schools. School Effectiveness and School Improvement, 29(1), 91-112. https://doi.org/10.1080/09243453.2017.1385490

Hammer, M. (2012). The Intercultural Development Inventory: A new frontier in assessment and development of intercultural competence. In M. Vande Berg, R.M. Paige, \& K.H. Lou (Eds.), Student Learning Abroad (pp. 115-136). Sterling, VA: Stylus Publishing.

Hansuvadha, N., \& Slater, C.L. (2012). Culturally competent school leaders: the individual and the system. The Educational Forum, 76(2), 174-189. https://doi.org/10.1080/00131725.2011.653094

Keung, E. K., \& Rockinson-Szapkiw, A. J. (2013). The relationship between transformational leadership and cultural intelligence: A study of international school leaders. Journal of Educational Administration, 51(6), 836-854. https://doi.org/10.1108/JEA-04-2012-0049

Koester, J., \& Lustig, M.W. (2015). Intercultural communication competence: Theory, measurement, and application. International Journal of Intercultural Relations, 48, 20-21. https://doi.org/10.1016/j.ijintrel.2015.03.006

Lahdenperä, P., Gustavsson, H. O., Lundgren, M., \& von Schantz-Lundgren, I. (2016). The key role of the school principal's leadership in the schooling of newly arrived immigrant pupils in Sweden: Experiences from an interactive action research project. Open Journal of Leadership, 5(1), 20-30. https://doi.org/10.4236/oj1.2016.51003

Pedersen, P. J. (2010). Assessing intercultural effectiveness outcomes in a year-long study abroad program. International Journal of Intercultural Relations, 34, 70-80. https://doi.org/10.1016/j.ijintrel.2009.09.003

Perry, L. B., \& Southwell, L. (2011). Developing intercultural understanding and skills: Models and approaches. Intercultural education, 22(6), 453-466. https://doi.org/10.1080/14675986.2011.644948

Polat, S. \& Olcum, D. (2016). Characteristics of diversity leadership according to teachers. Anthropologist, 24(1), 64-74. https://doi.org/10.1080/09720073.2016.11891990 


\section{Macrothink}

Pöllmann, A. (2016). Habitus, reflexivity, and the realization of intercultural capital. The (unfulfilled) potential of intercultural education. Cogent Social Sciences, 2(1), 1-12. https://doi.org/10.1080/23311886.2016.114991

Taylor, S. (2014). Globally-minded students: Defining, measuring and developing intercultural sensitivity. The International Schools Journal, 33(2), 26-34.

Vassallo, B. (2016). School leaders' perceptions on intercultural education. The Online Journal of New Horizons in Education, 6(4), 171-177.

Zembylas, M. (2010). The emotional aspects of leadership for social justice. Implications for leadership preparation programs. Journal of Educational Administration, 48(5), 611-625. https://doi.org/10.1108/09578231011067767

Zembylas, M., \& Iasonos, S. (2010). Leadership styles and multicultural education approaches: an exploration of their relationship. International Journal of Leadership in Education, 13(2), 163-183. https://doi.org/10.1080/13603120903386969 